\title{
Por uma cidadania de primeira classe: supremacia racial e o debate sobre integração na imprensa afro-americana na Primeira Guerra Mundial (1917- 1919)
}

\author{
Flavio Thales Ribeiro Francisco ${ }^{1}$
}

Resumo: O objetivo deste artigo é o de compreender a formação de hierarquias raciais no pós-abolição e o debate na imprensa negra sobre a integração da população negra nos Estados Unidos durante a Primeira Guerra Mundial. Os periódicos Chicago Defender e The Crisis expressaram os anseios do ativismo negro nas primeiras décadas do século XX, galvanizados pela atuação dos combatentes negros no conflito no Velho Continente. A Grande Migração e a participação dos negros na Primeira Guerra mundial foram consideradas dois eventos impulsionadores de uma cidadania de primeira classe para os negros. racial.

Palavras-chave: Ativismo afro-americano; imprensa negra; Estados Unidos; supremacia

\begin{abstract}
This article goes on to comprehend the emergence of racial hierarchies in postabolition era and the debate of Black press on the integration of African Americans during First World War. The periodicals Chicago Defender and The Crisis expressed the aspirations of the Black activism in early decades of Twentieth Century, galvanized by the role played by Black soldiers in the conflict. The Great Migration and First World War were regarded as the key events that would promote a first class citizenship for African Americans.
\end{abstract}

Keywords: African American activism; Black Press; United States; Racial Supremacy.

\section{Introdução}

Em 1863, Martin Delany, figura importante entre as lideranças negras nos Estados Unidos, procurou colocar em prática a sua ideia de organizar o alistamento de negros para as tropas da União que combatiam os Confederados na Guerra Civil (1861-1865). A percepção, naquele momento, era a de que a vitória do presidente Abraham Lincoln no conflito contra os estados rebeldes do sul promoveria a cidadania da população negra com o desmantelamento da escravidão no país. Delany conseguiu um encontro com Lincoln somente em 1865 e, através da sua capacidade de persuasão, oficializou a formação de um batalhão negro sob sua liderança. A maioria dos alistados era formada por escravos fugidos que cumpriram um papel ativo em uma guerra na qual cerca de 750 mil pessoas morreram.

A participação de Martin Delany na Guerra Civil foi marcante, mas o que torna a sua

1 Pós-Doutorando em História pela UNESP-ASSIS. Email: flaviusnet@hotmail.com . 
trajetória interessante é o fato de ele ter sido considerado um dos pais do Nacionalismo Negro. ${ }^{2}$ Em 1850, Delany foi obrigado a deixar a faculdade de medicina da Universidade de Harvard, após o protesto contra a presença de estudantes negros na instituição, e testemunhou aprovação da Fugitive Law, lei que permitia aos senhores capturarem escravos fugidos em estados não escravocratas (FRANKLYN; SCHWENINGER , 1999). Em um momento de frustração com práticas e políticas que inviabilizavam uma cidadania negra, Martin Delany direcionou o seu olhar para além das fronteiras norte-americanas, reforçando a necessidade dos negros criarem a própria nação (GILROY, 1998). Em sua obra The Condition, Elevation, Emigration and Destiny of the Colored People of the United States, Politically Considered, demonstrou como outros povos europeus e as comunidades judaicas se organizavam para conquistar autonomia. Aos negros dos Estados Unidos que aspiravam pela igualdade de direitos, restava apenas como alternativa a formação de uma comunidade nacional em uma outra região das Américas. Portanto, a integração dos negros à democracia norte-americana, na perspectiva de Delany, era uma realidade distante.

A emigração de negros para a América latina e o continente africano foi debatida já no início do século XIX, principalmente por escravocratas que não viam com bons olhos a formação de comunidades de negros livres nos Estados Unidos. O principal argumento era o de que os negros escravizados se entusiasmavam com a possibilidade de conquista da liberdade ao testemunhar a experiências dos negros livres. Durante a luta pela independência das 13 colônias britânicas, alguns negros que participaram do conflito conquistaram a liberdade. Posteriormente, nos estados do norte, a escravidão perdeu sua força gradativamente, contribuindo para a ampliação de comunidades negras livres. Uma das principais iniciativas para resolver essa questão foi a criação da American Colonization Society em 1816, que tinha como objetivo a obtenção de terras fora do território norteamericano para o assentamento de negros livres (SAMPAIO, 2013). O tema da emigração causou grande controvérsia nas comunidades negras entre aqueles que não enxergavam a possibilidade de conquista de direitos e os que acreditavam que o destino da população negra estava nos Estados Unidos.

O periódico Freedom's Journal, criado em 1826, revelou os impasses das lideranças diante do debate sobre o lugar do negro livre no país. O jornal, o primeiro a ser publicado por negros, procurou difundir ideias que se opusessem aos argumentos dos defensores da escravidão. Contudo, os seus editores, foram manifestando posições diferentes sobre os caminhos a serem trilhados para superar as barreiras raciais. Samuel Cornish, que posteriormente se engajaria em organizações

2 Ideologia que defende a autonomia dos negros em relação à nação, defendendo a formação de uma comunidade negra no interior do Estado nacional. 
antiescravistas e abolicionistas, expressou a sua crença na integração racial, já John Russwurm se envolveu com os projetos de colônias afro-americanas no Caribe, especulando sobre a possibilidade de assentamento no Haiti. Devido a outros compromissos profissionais, Cornish deixou a edição do jornal, mas retornou para reerguer o Freedom's Journal posteriormente, após a perda de um grande número de leitores incomodados com ênfase de Russwurm sobre esquemas de emigração de afroamericanos. O século XIX, na perspectiva dos negros livres, foi marcado pelas incertezas sobre uma cidadania negra e a permanência na América do Norte (HUTTON, 1992).

A Guerra Civil, como mencionado acima, despertou o ânimo de lideranças como Martin Delany, que já havia desistido das possibilidades de supressão da escravidão e da integração dos libertos. Ainda durante o conflito entre as tropas da Confederação e da União, escravos que fugiam das fazendas procuravam pela assistência das tropas do Norte, consideradas como agentes de destruição das relações escravocratas nos estados do Sul. Na Carolina do Sul, já em 1861, iniciou-se um experimento com 10 mil escravos que foram abandonados pelos proprietários e assumiram a responsabilidade de administrar as atividades nas terras que habitavam (SCHNEIDER, 2007, P. 325). As plantações de algodão logo foram substituídas por milho e batata para a subsistência. $\mathrm{O}$ conflito impulsionou as lutas pela liberdade e possibilitou as primeiras experiências de libertos como combatentes nas tropas da União ou como fazendeiros autônomos sem a supervisão dos senhores.

A abolição da escravatura, em 1863, foi celebrada pela população negra e tratada como um encaminhamento natural para afirmação de uma cidadania de primeira classe, na qual os negros desfrutariam de todos os direitos oferecidos aos cidadãos brancos. Entretanto, o fim da Guerra Civil apenas abriu um campo para novas disputas políticas em torno do lugar dos negros na sociedade norte-americana. $\mathrm{O}$ assassinato de Abraham Lincoln foi consequência das tensões não resolvidas que permaneceriam pelos próximos anos. Andrew Johnson, ao assumir a presidência, costurou uma aliança com as elites sulistas, possibilitando a reestruturação de uma hierarquia racial no pósabolição. Nos estados do Sul, os Black Codes foram aprovados teoricamente para regular a situação dos libertos, mas na prática serviram como instrumentos de opressão e controle dos trabalhadores negros. A ascensão de uma cidadania negra foi inviabilizada por leis que deram um poder desproporcional aos grandes proprietários de terra que utilizaram o capital político para estruturar um novo regime de exploração do trabalho dos negros nos estados do sul (FONER, 1988). A guerra devastara a economia algodoeira e era necessário que ações fossem tomadas rapidamente para o reestabelecimento da agricultura de exportação. 
Políticos de uma ala radical do Partido Republicano, entretanto, afirmavam que o sufrágio dos afro-americanos era um dos elementos chaves para a recuperação do Sul sob a intervenção do Norte, o governo federal deveria garantir a igualdade de direitos e promover a cidadania dos negros. Republicanos como Charles Sumner e Thadeus Stevenson articularam uma forte oposição ao presidente Andrew Johnson, e questionaram, em embates no congresso norte-americano, o excesso de concessões à classe dos proprietários de terras que comprometia as iniciativas de inclusão dos libertos. Por outro lado, entre iniciativas individuais e coletivas, os libertos enfrentavam no cotidiano as tentativas de controle sobre os seus corpos. A violência proporcionada pelos Black Codes revelou a profundidade dos antagonismos raciais, levando os republicanos a apoiarem ações mais incisivas para assegurar a igualdade de direitos. A aprovação da Décima Quarta Emenda da Constituição, em 1868, expressou o movimento de apoio às políticas para a integração racial nos estados do Sul, assegurando por lei a cidadania de pessoas nascidas no território norte-americano e a igualdade de direitos independentemente da raça (Ibidem, 1988).

Neste contexto no qual republicanos moderados e radicais manifestavam o compromisso com a promoção de uma cidadania negra, a Agencia dos Libertos cumpriu um importante papel na integração da população negra através da organização de instituições e recursos para os menos abastados. A instituição foi fundamental na construção de entidades educacionais e também procurou intervir na relação entre os grandes proprietários de terra e os libertos, garantindo a transição da escravidão para o trabalho livre. Através da implementação de um conjunto de políticas para o progresso da população negra no período da Reconstrução, surgiram também as tradicionais universidades negras, como Howard e Fisk, que ao longo da história colaborariam para formação de uma elite política e intelectual. Entretanto, os republicanos radicais perderam força no partido e não foram capazes de sustentar as iniciativas de inclusão da população negra. Os políticos sulistas logo retomaram poder e rearticularam atores e instituições no sentido de estabelecer uma ordem social estruturada pela segregação racial. Por um curto período de tempo, a população negra, ainda concentrada nos estados do sul, vislumbrou um processo de integração social, mas a reação racista acabou determinando o lugar dos negros nas margens da sociedade norte-americana.

A hierarquia racial que se estabeleceu no período posterior ao retrocesso nas políticas integracionistas limitou o ativismo negro que se rearticulava no pós-abolição. A luta pela igualdade de direitos perdeu espaço para um conjunto de ações que promoviam as instituições negras sem necessariamente afetar a estrutura segregada das comunidades do Sul. Na última década do século XIX, Booker T. Washington ascendeu como a principal liderança e referência de uma agenda 
política que enfatizava a importância de uma educação técnica e a difusão do empreendedorismo entre os negros sulistas. Washington definiu a sua abordagem em uma cultura segregacionista, observando que antes que os negros almejassem a integração era necessário estabelecer as bases para o desenvolvimento de suas próprias comunidades. A perspectiva moderada do líder negro atraiu a atenção de políticos brancos, interessados no discurso que não desafiava a hierarquia racial e apontava para estratégias coletivas restritas ao universo dos negros.

A trajetória de Washington teve como evento marcante o seu discurso de Atlanta, em 1895, para uma plateia predominantemente branca, no qual fez a observação de que as agitações pela igualdade de direitos deveriam ser substituídas pelo trabalho duro e o desenvolvimento econômico dos negros em um "Novo Sul” (WASHINGTON, 1995). Para Washington, através do trabalho na agricultura e da formação de empreendedores, os negros poderiam progredir e demonstrar a capacidade para o exercício de cidadania nos Estados Unidos. De certa forma, o líder negro referendou a segregação racial e delimitou a ações da população negra a uma estrutura social racializada e extremamente rígida. O sucesso de Booker T. Washington como representante dos negros reconhecido por diversas autoridades brancas se deu justamente no momento em que a Suprema Corte, em 1896, decidiu favoravelmente pela interpretação que afirmava que a separação de grupos raciais não violava a Constituição norte-americana, desde que brancos e negros tivessem acesso aos mesmos serviços e recursos. A decisão do caso Plessy vs. Ferguson ${ }^{3}$ deu força à doutrina “separados, mas iguais", legitimando a segregação de espaços públicos e privados nos estados do Sul.

\section{Ascensão dos novos negros e a institucionalização do ativismo}

Os códigos raciais aplicados em níveis locais, como observamos acima, inviabilizaram uma agenda de luta pela igualdade de direitos. A grande maioria da população negra, na última década do século XIX, ainda se concentrava no Sul do país e a expectativa de integração era muito pequena. A situação mudou a partir da segunda década do século XX, com a Primeira Guerra Mundial. Cidades como Chicago, Nova Iorque, Detroit e Boston, que apresentavam uma economia vigorosa, sobretudo com a consolidação da indústria no norte, transformaram-se em polos de atração de trabalhadores negros. A inserção, ainda que limitada, dos negros ao mercado de trabalho nas cidades do norte foi consequência da interrupção no fluxo de imigrantes europeus para os

3 Por 7 a 1, os juízes da Suprema Corte norte-americana decidiram a favor da constitucionalidade da segregação racial nos estados da União. 
Estados Unidos após o inicio da guerra no Velho Continente e também do recrutamento de trabalhadores brancos para as forças armadas enquanto o país aguardava a possibilidade de entrar no conflito. Agentes contratados pelas indústrias passaram a circular pelas cidades do Sul para informar os trabalhadores negros sobre as oportunidades de emprego nas cidades do Norte.

Assim, iniciou-se o deslocamento de milhares de migrantes negros para as cidades do norte, conhecido na historiografia norte-americana como a Grande Migração. Ao longo do século XIX, as comunidades de negros livres instaladas nos estados onde a escravidão havia sido abolida formavam apenas pequenos grupos nas cidades do Norte. Entretanto, a partir de 1914, as comunidades começaram a crescer de maneira acentuada com a migração, alterando decisivamente o mapa demográfico. Entre 1915 e 1930, cerca de 3,4 milhões de negros se deslocaram, transformando o perfil racial de algumas cidades (GROSSMAN, 1989). Na cidade de Chicago, por exemplo, entre 1910 e 1920, a população de negros saltou de cerca de 15 mil para 90 mil. A pequena população negra que vivia espalhada pela cidade na última década do século XIX se transformou em um cinturão negro concentrado na zona sul. Nesse mesmo período, a população negra de Nova Iorque chegaria a 150 mil, concentrando-se no mítico bairro do Harlem.

Assim as comunidades negras do norte possibilitaram a formação de uma diversidade de entidades sociais e políticas e a emergência de novas lideranças negras nos Estados Unidos. A abordagem moderada de Booker T. Washington passou a ser questionada por uma geração de militantes que se articulava em diferentes organizações que desafiavam as hierarquias raciais estruturadas na sociedade norte-americana. Dentre as lideranças podemos destacar William DuBois, Ida B. Wells, James Weldon Johnson, Hubert Harrison, Marcus Garvey, Willliam Trotter e Alain Locke. DuBois, o primeiro negro a conquistar o título de $\mathrm{PhD}$ na Universidade de Harvard, de maneira contundente contestou as posições políticas de Booker T. Washington, reforçando a importância da luta pela igualdade de direitos e enfatizando os limites do progresso econômico enquanto via de integração social (DUBOIS, 1999). William Dubois ganhou notoriedade com seu ativismo e produção intelectual, destacando-se como um dos principais articuladores da National Association for Advancement of Colored People (NAACP), em 1909. Esta organização, formada a partir de um quadro inter-racial de ativistas, cumpriu um importante papel desafiando práticas racistas nas instituições privadas e públicas, além de defender o direito de cidadãos negros contra as incongruências da justiça norte-americana viciada pelo racismo.

Ida B. Wells, que também fez parte do quadro de militantes da NAACP, destacou-se pela luta contra o linchamento de cidadãos negros nos Estados Unidos. Ao lado de Mary Terrel Church, 
foi uma das representantes das mulheres negras no ativismo negro em uma linhagem de figuras como Soujourne Truth, Hurriet Tubman, Mary Ann Chadd e Ana Cooper. Além de atuar no movimento sufragista, Wells denunciou as inúmeras práticas de violência perpetradas contra cidadãos negros nos Estados Unidos. Em seus discursos e escritos, a líder negra apontou as inconsistências de alegações de que homens negros sistematicamente violentavam mulheres brancas. O seu argumento era o de que as representações de homens negros estupradores foram concebidas como estratégia de dominação para desestimular a competição entre trabalhadores negros e brancos no mercado de trabalho. Ida B. Wells colocou em evidência o conjunto de estratégias de opressão racial que possibilitou a reorganização de uma hierarquia racial no período pós-abolição (SILKEY, 2015).

Em meio a essa emergência de novas lideranças, é possível identificar o papel ativo de negros originários do Caribe britânico, que se destacaram em uma linhagem de militantes radicais no ativismo negro norte-americano. Hubert Harrison ascendeu como uma das grandes referências do socialismo negro (PERRY, 2010). A sua trajetória, de certa forma, acabou reproduzindo uma tendência comum na experiência de ativistas negros com o Partido Socialista e, posteriormente, o Partido Comunista. Em um primeiro momento, Harrison foi um entusiasta do Partido Socialista, defendendo entre os membros do partido a importância da colaboração inter-racial e da promoção do socialismo entre os afro-americanos como estratégia de fortalecimento da luta contra o capitalismo norte-americano. Entretanto a estrutura do Partido Socialista, imerso na cultura racial dos Estados Unidos, revelou práticas discriminatórias que levaram Harrison a deixar o partido em 1915 e apostar em suas próprias iniciativas para difundir o socialismo entre os negros do Harlem. Através da organização Liberty League e da publicação do jornal The Voice, promoveu debates sobre o socialismo, a questão racial e o imperialismo, inserindo os afro-americanos em um contexto internacional.

Outra figura originária do Caribe britânico com grande influência no ativismo negro do período foi Marcus Garvey. O jamaicano iniciou a sua militância antes de imigrar para os Estados Unidos, inspirando-se na agenda de Booker T. Washington de promoção de uma educação para o empreendedorismo. Garvey chegou a trocar cartas com Washington, com a expectativa de recriar na Jamaica instituições de educação profissional e técnica nos moldes das promovidas pelo líder norteamericano. No entanto, ao fazer uma jornada pelo Sul dos Estados Unidos, Marcus Garvey percebeu os limites da agenda de Washington em um regime segregacionista que assolava as comunidades sulistas. Quando se instalou em Nova Iorque e iniciou a sua militância nas esquinas da 
cidade, o jamaicano passou a defender a ideia de retorno para o continente africano, retomando justamente projetos nacionalistas do século XIX como o de Martin Delany (STEIN, 1986). Através de UNIA - Universal Negro Improvement Association - , Garvey conseguiu atrair a atenção dos negros do Harlem, transformando-se numa liderança popular. Em seu projeto, a criação de colônias de afro-americanos e outros grupos afrodescendentes na África era parte de um movimento de redenção da raça negra, que seria inviável em cooperação com as populações brancas. As ideias de Garvey ganharam projeção internacional através da publicação do jornal Negro World, alcançando populações negras no Caribe, nos países africanos e, até mesmo, entre os brasileiros (FRANCISCO, 2013). O jamaicano foi uma figura influente até meados da década de 1920, antes que fosse preso e deportado para a Jamaica por se envolver em um caso de fraude de correspondências.

A Grande Migração também contribuiu para o crescimento e fortalecimento da imprensa negra no norte do país, onde a repressão sobre jornalistas e empastelamentos de redações não eram comuns. Na virada entre o século XIX e XX, os jornais negros, apesar de instrumentos fundamentais para a mobilização política, ainda sofriam devido a uma restrita base de leitores, penando para manter uma receita capaz de manter a circulação. Entretanto, a migração de milhares de trabalhadores negros e o aumento da taxa de alfabetização promoveram o processo de profissionalização do jornalismo afro-americano (JORDAN, 2001). O Chicago Defender, jornal semanal que foi o principal periódico negro no entre guerras, começou a circular em 1905 pelas esquinas dos quarteirões habitados majoritariamente pelos negros. O Defender, contudo, iniciou a sua operação de maneira artesanal. Robert Abbott, o seu fundador e editor, produzia o periódico no mesmo quarto alugado onde dormia. A publicação do jornal surgiu como uma alternativa à carreira de advogado, frustrada pelas barreiras raciais impostas aos profissionais negros. Abbott, um migrante originário do estado da Geórgia, inúmeras vezes pensou em encerrar a publicação do Defender, porém a formação de uma comunidade negra em Chicago impulsionou as vendas do jornal, transformando-o em um dos negros mais ricos do país na década de 1920.

O periódico, uma modesta folha de circulação local até 1915, atingiu uma circulação nacional, promovendo a migração de trabalhadores negros e criticando veementemente o segregacionismo nos estados sulistas (DESANTIS, 1993). As cidades do Norte foram representadas nas páginas do Defender como espaços de inclusão dos negros, enquanto o Sul do país foi retratado como espaço de reconfiguração de uma hierarquia racial após a escravidão. No amplo espectro político que se formou com a ascensão dos "novos negros", Robert Abbott emergiu como uma liderança que lutava pela integração racial e acreditava que o capitalismo norte-americano, presente 
em cidades como Chicago, Nova Iorque, Detroit e Pittsburgh, incorporaria em um período curto de tempo os afro-americanos à modernidade.

Seguindo os passos do Chicago Defender, jornais negros de outras cidades passaram a circular regionalmente e nacionalmente, como o New York Age, o Baltimore Afro-American, o Norfolk Journal and Guide, o Boston Guardian, o Pittsburgh Courier e o Negro World. Esses periódicos cumpririam um papel importante na formação de uma esfera pública negra, na qual questões relacionadas às experiências negras nos Estados Unidos ganhavam destaque. A revista The Crisis, em meio aos jornais semanais, dedicou-se a publicação de artigos literários e de análises de eventos que tinham impacto sobre os afro-americanos, revelando um perfil mais intelectualizado. $\mathrm{O}$ periódico começou a circular em 1910 como órgão de difusão de ideias de ativistas da NAACP, divulgando também as atividades da organização política. Williams DuBois, enquanto um dos intelectuais e ativistas mais ativos naquele momento, atuou como editor da revista e procurou utilizá-la como um meio de aproximação de sua produção intelectual de um público mais amplo (NASCIMENTO, 2015). O periódico iniciou a sua circulação com 1000 exemplares e atingiu 100 mil na década de 1920.

O novo negro, representado e difundindo na literatura e na imprensa negra, não somente revelou uma abordagem mais crítica em relação ao racismo, mas também a emergência de um negro alinhado à modernidade norte-americana, reforçando a crença de que os centros da industrialização norte-americana poderiam transformar, a partir da inclusão dos negros ao mercado de trabalho, a estrutura social e desmantelar as hierarquias raciais em diferentes regiões dos Estados Unidos. Quando a Primeira Guerra Mundial se iniciou na Europa e passou-se a especular sobre a possibilidade de entrada dos norte-americanos no conflito, a militância negra identificou no evento um momento privilegiado para reforçar a importância da integração racial, clamando pelo recrutamento dos negros para o exército. A atuação dos combatentes negros demonstraria a lealdade dos afro-americanos com a nação. Assim como no período da Guerra Civil, a Primeira Guerra Mundial entusiasmou diversos segmentos da população negra que acreditaram que o conflito abriria as frestas para inclusão e mobilidade social.

\section{Primeira Guerra Mundial e possibilidade de integração}

Se a Primeira Guerra Mundial foi considerada por grande parte dos negros uma oportunidade para demonstrar a lealdade à nação norte-americana e promover a inclusão, os 
segmentos da população branca resistentes à ascensão dos negros enquanto cidadãos de primeira classe compreenderam que o conflito no continente europeu poderia ser uma ameaça a uma ordem social estruturada por hierarquias raciais. Os próprios militares criaram barreiras para o recrutamento de negros, comprometendo o ingresso nas forças armadas. Os jornais da imprensa negra, dentre eles o Chicago Defender, denunciaram as inúmeras práticas discriminatórias, que obrigavam os negros a repetidamente tentar o alistamento. Em 1917, quando os Estados Unidos entraram na Guerra, a militância negra reforçou ainda mais o clamor pelo recrutamento de negros, principalmente quando o presidente Woodrow Wilson justificou a participação do país a partir da retórica da "guerra por democracia". Na revista The Crisis, foi observada a contradição entre a participação dos negros na guerra e as barreiras raciais que inviabilizavam a integração:

O negro é obrigado a pagar os seus impostos. Agora ele foi chamado para lutar pelo seu país. No futuro, será possível sob a lei escrita, ou tais leis tradicionais, impor aos negros os deveres e negá-los o direito a uma cidadania? Se é dito aos negros que eles tem uma missão, é possível afirmar que no futuro eles poderão estar numa lista de recrutamento, mas não poderão votar? ( The Crisis, 30 de novembro de 1917, p.78) [Tradução do autor].

Entretanto, como observa a historiadora Adriene Lenthz-Smith (2009), a questão do recrutamento de negros não estava circunscrita aos debates sobre cidadania, há também um elemento crucial nesse momento de mudanças que é a disputa sobre as masculinidades. O ingresso de negros nas forças armadas fomentaria a competição entre homens negros e brancos, a possibilidade de vestir o uniforme e representar os Estados Unidos na Primeira Guerra, de certa forma, elevaria o status dos homens negros. Mulheres e homens negros passaram a tratar os soldados afro-americanos como guerreiros capazes de confrontar a violência racial e de desestabilizar a supremacia racial nos Estados Unidos. Entre alguns segmentos da população branca norte-americana, contudo, a possibilidade de negros receberem treinamento militar foi considerada uma afronta, questionava-se a lealdade dos afro-americanos à nação.

A questão do recrutamento criou tensões entre brancos e negros, sobretudo em bases do sul, onde os cidadãos desafiavam a autoridade dos militares negros uniformizados que estavam na expectativa do embarque para a França. Em Houston tivemos o caso mais trágico. Ao reagirem aos atos violentos de policiais brancos sobre mulheres negras, oficiais negros, já cansados do preconceito racial cotidiano, empunharam armas e desafiaram a estrutura social do Jim Crow ${ }^{4}$

4 Termo utilizado para se referir ao regime segregacionista nos Estados Unidos. 
atirando em cidadãos da cidade. O levante, embora tenha entusiasmado parte do regimento, não foi o suficiente para incitar a raiva e o senso de justiça de todos os militares negros, desarticulando-se em poucas horas. Em seguida, aqueles que haviam protagonizado o evento foram julgados e condenados. Alguns foram para a forca, outros passaram o resto da vida na cadeia, e uma parte foi sentenciada com condenações leves. Apesar de tudo, o acontecimento reforçou a convicção de ativistas de que a lealdade dos soldados negros durante a guerra teria como retribuição o direito a uma cidadania de primeira classe.

Cerca de 200 mil negros participaram da Primeira Guerra Mundial, 42 mil foram para as linhas de frente do conflito no continente europeu (Ibidem, p. 34). As tensões que se revelaram já nos campos de treinamento em território norte-americano preocuparam os ativistas e jornalistas da imprensa negra que discutiam a reprodução de práticas discriminatórias nos acampamentos em terras estrangeiras. As questões debatidas nos periódicos negros tiveram repercussão, milhares de cidadãos americanos e algumas organizações políticas fizeram pressão sobre as autoridades militares para que investigassem as alegações de segregação nas Forças Armadas. Em Declaração, Newton Baker, Secretário da Guerra, procurou responder os rumores de discriminação com uma declaração, afirmando que o departamento investigaria qualquer caso de injustiça racial, mas também clamando por uma causa nacional em um momento de guerra:

Respondendo a vários telegramas e cartas de protesto enviados para o departamento, que chamaram a minha atenção, sobre as alegações de discriminação contra os recrutas negros, eu gostaria de dizer que uma investigação sobre o problema acabou de ser encaminhada.

Como vocês sabem, a minha política é a de desencorajar qualquer discriminação baseada na raça. Essa política não foi adotada meramente como um ato de justiça para todas as raças que fazem parte da sociedade americana, mas como uma salvaguarda para uma instituição que passa por um dos grandes momentos de sacrifício. Qualquer desordem racial poderia comprometer o engajamento no conflito.

Ao mesmo tempo não há intenção da parte do Departamento de Guerra de promover a questão racial. Neste momento de emergência nacional, homens brancos e negros têm sido chamados para defender a honra do nosso país. Seguindo a lógica, alguns lutarão nas trincheiras e outros contribuirão em outras operações atrás das linhas de fogo. (Chicago Defender, 8 de dezembro de 1917, p. 7) [Tradução do autor].

No periódico Chicago Defender é possível identificar uma oscilação entre ceticismo e entusiasmo. Se por um lado as alegações de discriminação no exército norte-americano pareciam ter exportado para a Europa a supremacia racial, por outro havia uma leitura otimista sobre o cenário 
socioeconômico. A Grande Imigração, com o deslocamento de trabalhadores negros para os grandes centros industriais do país, iniciara um processo de inserção dos negros no mercado de trabalho. No entanto, a Primeira Guerra Mundial promoveria uma cidadania negra de primeira classe, o Chicago Defender desenhava um cenário positivo não somente para os afro-americanos, mas também para todas as populações negras do mundo. De acordo com o jornal, o conflito se apresentava como a oportunidade para que o homem negro demonstrasse a sua capacidade e desmantelasse todos os argumentos sobre a sua inferioridade. Os africanos e os caribenhos, por exemplo, já haviam ganhado o reconhecimento dos franceses, que em retribuição à lealdade durante o conflito, os incorporariam como cidadãos do império. Senegaleses, marroquinos e combatentes da Martinica "atenderam ao chamado dos franceses" e colocaram as suas vidas em risco por uma nação que os “reconhecia como iguais", e não como povos subjugados e inferiores. O Chicago Defender não escondia suas expectativas positivas:

[...] Nossos soldados têm grande responsabilidade. "Se eles provarem que são tão capazes quanto os brancos", diz o Chicago Tribune, "no aspecto disciplinar, auto-domínio e coragem, eles farão muita coisa para diminuir o preconceito racial".

Nós estamos sob julgamento. Todos nós precisamos apoiar nossos soldados, é necessário animá-los e encorajá-los. Através da lealdade e uma boa medida de devoção, nós esperamos ganhar, não somente a liberdade na América, mas uma cidadania integral e inquestionável. (Chicago Defender, 5 de janeiro de 1918, p.10) [Tradução do autor].

A The Crisis, com menos entusiasmo, em um tom mais crítico, publicou uma variedade de artigos que, a partir de diferentes ângulos, questionou a democracia norte-americana e ressaltou as lutas históricas das lideranças negras. Além da memória da participação de soldados negros na Guerra Civil, o periódico também fez referência aos combatentes negros que participaram da Guerra Hispano-Americana, com imagens e textos que traziam uma narrativa histórica da lealdade dos afro-americanos aos Estados Unidos. Na edição de junho de 1917, o editorial da revista trouxe as observações de Mary White Ovington, que demonstrou a dificuldade de se defender a existência de uma democracia norte-americana a partir das experiências dos afro-americanos, com a discriminação no funcionalismo público, a negação do direito a um julgamento justo e ao voto, comprometendo a representação política dos negros no congresso norte-americano. Na mesma seção, foi reproduzido o sermão de Stephen Wise, ironizando o fato de que foi necessário os negros lutarem em terras estrangeiras para se reconhecer os limites da democracia nos Estados Unidos: 
Nós precisamos deixar nosso próprio país para perceber algumas injustiças. Nós fomos surpreendidos por rumores de sentimentos de desafeto e revolta dos negros contra a nação, rumores injustos sobre a raça negra. Os negros são tão leais à nação quanto os brancos. Este não seria o melhor momento para não somente demonstrar um gesto de generosidade em relação negro, mas também para rever a nossa atitude e tornar possível para que ele possa cooperar com os esforços de guerra com entusiasmo e alegria? A ocasião é favorável. Podemos nós como nação sermos justos, em nossa paixão por nobreza e justiça mais do que a beleza da generosidade, lidar sabiamente com o nosso grande erro na experiência americana? (The Crisis, junho de 1917, p. 116) [Tradução do autor].

Apesar da diferença de abordagens dos periódicos, ambos consideravam que aquele era um momento de mudanças para a população afro-americana. O Chicago Defender incrementou a sua cobertura com a publicação de cartas de soldados que atuaram nas linhas de frente do conflito. O jornal reforçou o tom patriótico dos combatentes negros, com relatos eufóricos sobre a experiência de representar os Estados Unidos em batalhas no continente europeu. O sargento Clarence Hudson, por exemplo, além de manifestar a sua admiração pelo Chicago Defender, reproduziu o discurso oficial do governo norte-americano, de união de povos em uma luta pela afirmação dos ideais democráticos. Hudson também fez o relato de suas experiências pelas regiões interioranas da França, destacando a recepção positiva dos franceses sobre os soldados negros. No trecho final de sua carta, Hudson ainda revelou o seu sentimento antigermânico elevado pelo clima da guerra:

Agora eu vejo a Grande Guerra. As batalhas em Verdun e Ypres serão sempre relembradas. Eu entrei nesta guerra com tudo isso em mim. Eu não poderia resistir ao sentimento de querer participar desta realidade. A minha primeira inspiração para atravessar o oceano e lutar pelo destino da democracia veio de um desenho em quadrinhos que vi em um jornal noturno, no qual o Kaiser William, em um dragão mecânico de ferro e aço com armas disparando balas pelo seu nariz, olhava para os Estados Unidos e destruía cidades transformando as populações em massa de carne. $\mathrm{Na}$ cabeça do dragão estava o Kaiser com sua longa face cruel com o capacete imperial. Esta ilustração ainda está na minha mente. O seu clamor pela morte e aniquilação, que dura cerca de quatro anos, vai terminar.

Agora o heroísmo está em evidência, cada um faz a sua parte. Em breve, com fama, grandeza e glória nós retornaremos à "Terra da Liberdade e Lar dos Bravos", que amanhecerá com um belo dia. (Chicago Defender, 24 de agosto de 1918, p. 3) [Tradução do autor].

No entanto, o entusiasmo do ativismo negro foi arrefecendo na medida em que relatos sobre 
discriminação e tensão racial nas tropas foram divulgados pela imprensa. O Secretario da Guerra, uma vez mais, foi obrigado a fazer uma declaração para demonstrar o esforço do governo para garantir um tratamento justo aos militares negros. O Chicago Defender publicou um artigo, sem a identificação do autor, no qual manifestou a preocupação com a situação das tropas que retornavam aos Estados Unidos sem a garantia de que no futuro a igualdade de direitos fosse assegurada. A Primeira Guerra Mundial, que em um primeiro momento poderia ser um elemento impulsionador num movimento de promoção da cidadania negra, foi tratada no texto como mais um evento de reprodução de hierarquias raciais.

Alguns dos primeiros norte-americanos a irem para as linhas de frente na França foram homens de peles negras. Eles e seus irmãos que chegaram depois têm demonstrado coragem e valor como combatentes, não devendo nada aos seus colegas brancos. Eles têm os mesmos interesses, os mesmos ideais, a mesma paixão pelo país que os soldados brancos. Eles merecem menos direitos que os seus colegas brancos? [...]

[...] Nós estamos planejando uma campanha de americanização da população estrangeira. Porém o homem negro não precisa de americanização. Ele já é essencialmente norte-americano, e está provando isso. O que ele realmente precisa é de justiça, respeito, oportunidade justiça que não irá tolerar discriminação contra ele, respeito pelo seu patriotismo, oportunidade para se educar e crescer, oportunidade para ajudar o seu país e sua geração como os seus irmãos brancos fazem. (Chicago Defender, 24 de agosto de 1918, p. 3) [Tradução do autor].

Já em texto publicado para a The Crisis, William Dubois destacou o papel das tropas negras na Primeira Guerra Mundial, tanto de senegaleses que lutaram ao lado de franceses, quanto de afroamericanos que contribuíram com o exército norte-americano como estivadores e soldados. No entanto, a vitória dos aliados no conflito, apoiados pelos Estados Unidos, foi ofuscada pelos relatos de discriminação e segregação dos soldados negros e do próprio DuBois, que testemunhou de perto as movimentações da guerra. A experiência dos afro-americanos foi marcada por ações sistemáticas de militares brancos de controle sobre os negros, com reestruturação de hierarquias raciais de padrão norte-americano em terras estrangeiras. As possibilidades de contato entre negros e brancos franceses foram sabotadas pelos brancos norte-americanos determinados a reproduzir a linha de cor na Europa. Se na perspectiva dos europeus, os afro-americanos foram fundamentais para "salvar a civilização", algumas autoridades militares os criticaram excessivamente por uma suposta desobediência e falta de disciplina. 
[...] Os soldados negros através da doçura conquistaram amigos em todos os lugares. Eles testemunharam o sofrimento de pessoas desventuradas, trabalhando e lutando entusiasmadamente para ajudá-los. Oficiais e civis de alta posição social competiram entre eles para demonstrar o máximo de consideração. Quando um oficial negro, acompanhado de uma senhorita francesa, entrou num café, os americanos brancos ressentidos se levantaram, enquanto os franceses nas outras mesas de maneira cortês o cumprimentaram.

Muitos dos brancos sulistas de alta patente comandados pelo General Ballou fizeram de tudo para prejudicar e desencorajar os homens negros - os fotógrafos não tiveram permissão para fotografa-los, por isso não há quase registros dos soldados negros [...]

[...] As palavras de reconhecimento do papel desempenhado pelos negros estivadores e dos combatentes se espalham, enquanto o exército norteamericano retornará ao país determinado a desprezar os oficiais negros e eliminá-los apesar do ótimo serviço prestado. E os soldados e estivadores? Eles retornarão amargurados e exaltados! Eles não mais se submeterão à casta racial norte-americana e amarão para sempre a França. (The Crisis, março de 1919, p. 222) [Tradução do autor].

Os periódicos, reproduzindo o sentimento de soldados e intelectuais negros, de certa forma, fizeram a previsão de que o retorno dos militares seria marcado por tensões raciais. As comunidades afro-americanas de diferentes partes do território alimentaram a esperança de que a participação dos negros na Primeira Guerra Mundial poderia impulsionar um amplo processo de integração racial. Contudo, além dos registros de discriminação e segregação de soldados negros durante o conflito no Velho Continente, confrontos entre brancos e negros se intensificaram com o retorno dos soldados. Enquanto os negros reivindicavam políticas de inclusão e igualdade de direitos, muitos dos soldados brancos exigiram os privilégios que tinham no mercado de trabalho antes da guerra. As clivagens ocasionadas pelos antagonismos raciais se reproduziram em cidades como New London, Bisbee, Coastville e Washington, capital do país. A mais violenta delas aconteceu em Chicago, em um conflito que se estendeu por mais de uma semana com 38 mortos e 530 pessoas feridas. A temporada de violência no ano de 1919 ficou conhecida como Verão Sangrento (ABU-LUGHOD, 2007).

A violência racial no momento de retorno de soldados da Primeira Guerra Mundial encerrou um período de entusiasmo para os que defendiam a tese de que a Grande Migração havia iniciado o processo de inclusão dos negros à modernidade norte-americana. No Chicago Defender, o editor Robert Abbott observou que os negros que retornavam da guerra tinham uma consciência política incompatível com a hierarquia racial da sociedade norte-americana, considerando negros e brancos como dois corpos "irreconciliáveis". No mesmo periódico, William S. Scarborough, reitor da 
Wilberforce University, afirmou que os militares não tinham a mínima noção de que ao enviar os negros para combaterem em nome da democracia estavam criando um problema para o futuro. Os soldados afro-americanos voltariam para os Estados Unidos exigindo um outro tratamento, surgiria um novo negro:

[...] Ele é completamente um novo homem, com novas ideias, novas esperanças, novas aspirações e novos desejos. Ele não se submeterá pacificamente às condições anteriores sem protestar vigorosamente e nós não deveríamos pedir que mantivessem um comportamento moderado. Esse é um novo negro que está entre nós, não deveríamos esperar também por um novo homem branco? A guerra tem revolucionado o mundo inteiro, mudando o modo de pensar e de agir. Novas pessoas com novos pensamentos devem assumir o fronte agora. (Chicago Defender, $30 \mathrm{de}$ agosto de 1919) [Tradução do autor].

A sensação de mudança perceptível na imprensa negra na segunda década do século XX não foi acompanhada por um entusiasmo de segmentos da população branca norte-americana. William S. Scarborough, assim como vários intelectuais negros do período, testemunharam a ascensão de um novo negro, associado a um processo de modernização da sociedade norte-americana, no entanto não havia um "novo homem branco" para encaminhar o processo de integração da população afro-americana. A violência do Verão Sangrento demonstrou ao ativismo negro que as práticas racistas estavam presentes em todo o território dos Estados Unidos, e não somente circunscrito aos estados do Sul.

\section{Conclusão}

Desde o fim da Guerra Civil, a sociedade norte-americana, em um embate entre forças conservadoras e progressistas, passou por inúmeras transformações nas relações raciais. $\mathrm{O}$ caso da Primeira Guerra Mundial, e dos eventos subsequentes, revelam alguns tímidos avanços para a população negra que migrou para o norte e as rearticulações de hierarquias estruturadas pela crença na raça. A geração New Negro, que contribuiu para a institucionalização do movimento negro nos Estados Unidos, desafiou, a partir de diferentes posições políticas e agendas, a supremacia racial norte-americana. Entretanto, o esforço do ativismo negro, que considerou o conflito na Europa uma oportunidade para reivindicar a igualdade de direitos, não foi capaz de abalar uma ordem social fraturada por hierarquias raciais. A imprensa negra, aqui retratada pelo jornal Chicago Defender e a revista The Crisis, procurou galvanizar o público negro com a participação de combatentes negros 
na Primeira Guerra Mundial, anunciando transformações para os afro-americanos. No entanto, ativistas e jornalistas negros não calcularam o grau de reação de segmentos racistas da população branca, seja resistindo no interior das forças armadas ou reivindicando violentamente privilégios no retorno das tropas. Os poucos avanços dos negros foram freados por um conjunto de eventos que reafirmou a supremacia racial como parte estruturante da sociedade norte-americana.

\section{Referências Bibliográficas:}

Fontes:

Chicago Defender: artigos eletrônicos entre 1910 e 1919 disponíveis no site www.chicagodefender.com;

The Crisis: (revista da NAACP): Exemplares completos disponíveis no site http://www.modjourn.org/journals.html .

\section{Livros e Teses:}

ABU-LUGHOD, Janet L. Race, space, and riots in Chicago, New York, and Los Angeles. New York: Oxford University Press, 2007.

BALDWIN, Davarian L. Chicago's Negroes: modernity, Great Migration and Black urban life. Chapel Hill: University of North Carolina Press, 2007.

CRONON, E. David. Black Moses: the history of Marcus Garvey and the Universal Negro Improvement Association. Madison: The University of Wisconsin Press, 1969.

DESANTIS, Alan Douglas. Selling the American Dream: The Chicago Defender and Great Migration of 1915-1919. Tese de Doutorado, Universidade de Indiana, 1993.

DUBOIS, W.E.B. As almas da gente negra. Rio de Janeiro: Lacerda Editores, 1999.

FONER, Eric. Reconstruction: America's unfinished revolution (1863-1877). New York: Harper \& Row, 1988.

FRANCISCO, Flavio Thales Ribeiro. Fronteiras em definição: identidades negras e imagens dos Estados Unidos e da África no jornal O Clarim da Alvorada (1924-1932). São Paulo: Alameda/FAPESP, 2013.

FRANKLYN, John Hope; SCHWENINGER, Loren. Runaway slaves: rebels on the plantation. New York: Oxford University Press, 1999.

GILROY, Paul. O Atlântico Negro. São Paulo: Editora 34, 2001.

GREGORY, James N. The southern diaspora: how great migrations of black and white southerners transformed America. Chapel Hill: University of North Carolina Press, 2005. 
GROSSMAN, James R. Land of Hope: Chicago, Black Southerners, and the Great Migration. University of Chicago Press, 1989.

HUTTON, Frankie. The early Black press in America, 1827-1860. Westport: Greenwood Publishing Group, 1992.

JONAS, Gilbert. Freedom's sword: the NAACP and the struggle against racism in America, 19091969. New York; London: Routledge, 2005.

JORDAN, William G. Black newspapers and America's war for democracy, 1914-1920. Chapel Hill: The University of North Carolina Press, 2001.

KEYSSAR, Alexander. The right to vote: the contested history of democracy in United States. New York: Basic Books, 2000.

LENTHZ-SMITH, Adriane Danette. Freedom struggles: African Americans and World War I. Cambridge: Harvard University Press, 2009.

MACLEAN, Nancy. Behind the Mask of Chivalry: The Making of the Second Ku Klux Klan. Oxford: Oxford University Press, 1994.

MORROW, Jr., John H. The Great War: an imperial history. New York: Routledge, 2005.

NASCIMENTO, Carlos Alexandre da Silva. Representando o "novo" negro norte-americano: W.E.B. DuBois e a Revista The Crisis, 1910-1920. Dissertação de Mestrado, Programa de Pós-Graduação em História Social da Universidade de São Paulo, 2015.

OTTLEY, Roi. The Lonely Warrior: The Life and Times of Robert S. Abbott. Chicago: H. Regnery Co, 1955.

PERRY, Jeffrey B. Hubert Harrison: The Voice of Harlem Radicalism, 1883-1918. Columbia University Press, 2010.

PRIDE, Armistead S. \& WILSON II, Clint C. A history of the black press. Washington, D.C.: Howard University Press, 1997.

SAMPAIO, Maria Clara Sales Carneiro. Não diga que não somos brancos: os projetos de colonização para afro-americanos do governo Lincoln na perspectiva do Caribe, América Latina e Brasil dos 1860. Tese de Doutorado, Programa de Pós-Graduação em História Social da Universidade de São Paulo, 2013.

SCHNEIDER, Dorothy; SCHNEIDER, Carl J. Slavery in América. New York: Facts on Life, 2007.

SILKEY, Sarah L. Ida B. Wells: lynching and transatlantic activism. Athens: Georgia University Press, 2015.

SIMMONS, Charles A. The African American Press: a History of News Coverage During National Crises, with Special Reference to Four Black Newspapers (1827-1965). Jefferson: McFarland \& Co., 1997.

SMETHURST, James Edward The African American Roots of modernism: from reconstruction to 
Sankofa. Revista de História da África e de Estudos da Diáspora Africana Ano IX, NXXIII, dezembro/2016

the Harlem Renaissance. Chapel Hill: The University of North Carolina Press, 2011.

STEIN, Judith. The World of Marcus Garvey: race and class in modern society. Baton Rouge: LSU Press, 1986.

WASHINGTON, Booker T. Up from slavery. Nova York: Dover Publications, 1995.

Recebido 20/10/2016 - Aprovado em 20/12/2016. 